\title{
Circumflex Coronary Occlusion: Classic ECG
}

David H. Spodick, MD, DSc

click an author to search for more articles by that author

Shown is an electrocardiogram of a 48-year-old man with typical onset of acute myocardial infarction. The electrocardiogram shows combined QRS-ST-T abnormalities virtually pathognomonic for the circumflex coronary artery occlusion (demonstrated on emergent catheterization): 1) acute inferior wall infarction with ST elevation greater in lead II than in lead III with abnormal Q waves (voltage criteria here) in II, III, and aVF; 2) posterior infarction: $\mathrm{R}$ larger than $\mathrm{S}$ in $\mathrm{V} 1$ and $\mathrm{V} 2$, as well as $\mathrm{R}$ duration $40 \mathrm{~ms}$ in $\mathrm{V} 1$ and $60 \mathrm{~ms}$ in V2, with tall, pointed, and symmetric T waves in V1-V3-the mirror image of posterior leads that would monitor the posterior left ventricular wall (anterior $\mathrm{R}$ waves are the reverse of posterior leads that would monitor the posterior left ventricular wall (anterior $\mathrm{R}$ waves are the reverse of posterior Q waves); 3) acute infarct abnormalities in V5 and V6, reflecting the lateral component of the infarct. Any one of these three are consistent with circumflex occlusion, and more common than the combination. The patient, a smoker, also has a vertical $\left(80^{\circ}\right)$ P wave axis, with "gothic" P waves in leads II, III, and aVF typical of pulmonary emphysema. The large inverted $\mathrm{P}$ wave may reflect left atrial enlargement, but this is uncertain with emphysema. ST-T changes in V5 and V6 represent a lateral ("apical") infarct component.

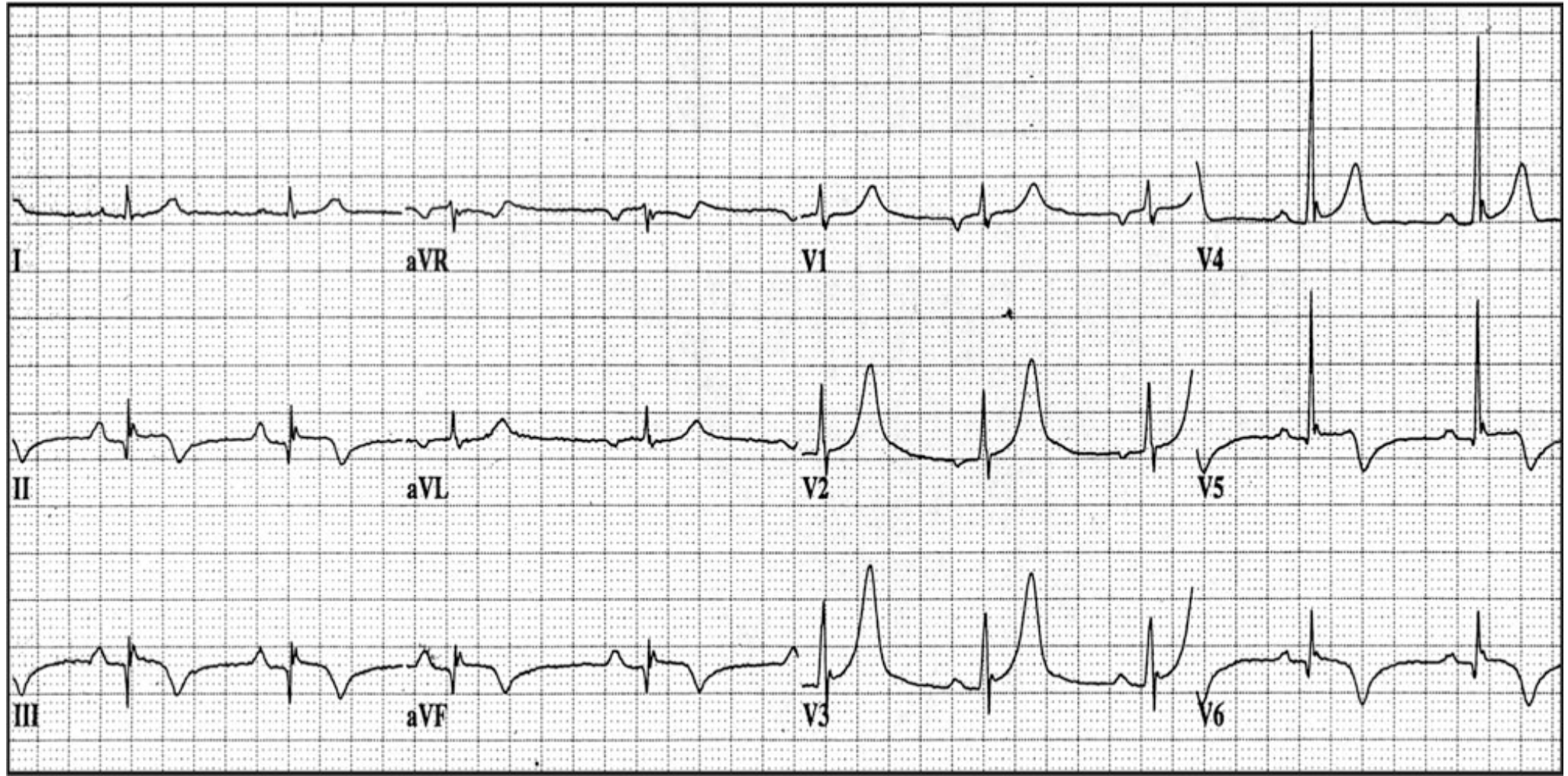

